Volume 9. Nomor 1. Januari 2014
Pandecta
htt//journal.unnes.ac.id/nju/index.php/pandecta

\title{
Pendidikan Tentang Pencegahan Kekerasan terhadap Perempuan dalam Dimensi Kejahatan Siber
}

\author{
Go Lisanawati ${ }^{\varpi}$ \\ Fakultas Hukum Universitas Surabaya, Surabaya, Indonesia \\ Permalink/DOI http://dx.doi.org/10.15294/pandecta.v9i1.2852
}

\begin{tabular}{l} 
Info Artikel \\
\hline Sejarah Artikel: \\
Diterima Oktober 2013 \\
Disetujui November 2013 \\
Dipublikasikan Januari 2014 \\
\hline Keywords: \\
crime; \\
torture; \\
women; \\
education \\
\hline
\end{tabular}

\begin{abstract}
Abstrak
Salah satu macam kejahatan yang berkembang pesat dewasa ini adalah kejahatan yang dilakukan secara elektronik, atau yang dikenal sebagai kejahatan siber. Kejahatan ini beragam bentuknya. Kehadiran Undang undang Nomor 11 Tahun 2008 tentang Informasi dan Transaksi Elektronik telah mengatur mengenai perbuatan yang dilarang terkait dengan informasi dan transaksi elektronik. Masalah kekerasan yang terjadi melalui online secara fakta menimbulkan permasalahan bagi perempuan. Masalah pencegahan kekerasan terhadap perempuan dalam dimensi kejahatan siber harus didesiminasikan kepada setiap orang, terlebih khusus kepada perempuan. Untuk itu setiap orang, khususnya dalam hal ini adalah perempuan, perlu untuk mendapatkan pemahaman pengetahuan yang baik tentang dampak kejahatan siber, dan potensi munculnya perempuan sebagai korban dari kejahatan tersebut, misalnya cyberstalking dan cyberpornography. Melalui pendidikan tersebut, diharapkan perempuan mendapatkan hak-haknya secara maksimal, khususnya yang terkait dengan hak memperoleh pendidikan dan kebebasan mengemukakan pendapatnya.
\end{abstract}

\section{Abstract}

One of the recent crimes which rapidly increase is crime which done through electronic means as known as cybercrime, in various forms. Law Number 11 of 2008 concerning Electronic Information and Transacation, as an exist law, prohibit criminal acts related with electronic information and transaction. In fact, violences through online medium is occuring problem for women. Therefor the prevention of the violence against women in cyber crime perspectives shall be disseminated to everybody, especially to women. Women shall aware with the impact of cyber crime and women as potential victims of cyber crime, such as cyberstalking and cyberpornography. Through education about the potential harm of cyber crime, it is wish that women can gain their rights maximized, especially in related with the rights of education and freedom of thought.

$\triangle$ Alamat korespondensi:

Jl. Ngagel Jaya Selatan 169. Surabaya 60284 Indonesia

E-mail: go_lisanawati@ubaya.ac.id
(C) 2014 Universitas Negeri Semarang ISSN 1907-8919 (Cetak) ISSN 2337-5418 (Online) 


\section{Pendahuluan}

Masalah perkembangan teknologi informasi dan komunikasi yang telah mengalami percepatan dalam konteks globalisasi sesungguhnya telah menempatkan manusia sebagai subjek dari percepatan dan perkembangan teknologi tersebut sendiri, yang menampati dua sisi yaitu sisi pelaku dan di lain pihak adalah sisi korban. Pada macam perkembangan tersebut seringkali muncul kejahatan dalam bingkai kecanggihan teknologi, tetapi yang seringkali tanpa pandang bulu untuk memilih pelaku atau korbannya.

Setiap perkembangan pada hakikatnya membawa efek seperti dua sisi mata uang yang masing-masing saling berkaitan dan tidak akan terpisahkan, yang berupa sisi positif dan sisi negatif. Harus diakui perkembangan teknologi informasi dan komunikasi telah membawa perubahan yang mendasar di dalam manusia melaksanakan kehidupan barunya. Manusia mendapatkan berbagai kemudahan di dalam melaksanakan kegiatankegiatannya. Manusia dapat melakukan perdagangan dengan cara yang mudah, murah, dan efektif tanpa harus pergi ke suatu tempat untuk melakukan kegiatannya. Namun demikian sisi negatifnya juga tidak kalah menariknya untuk diperhatikan mengingat dampak yang muncul telah mengancam kehidupan manusia, bahkan dapat dinyatakan informasi teknologi dan komunikasi juga dapat berdampak kepada masalah ketidakadilan dalam perspektif gender.

Melalui Penelitian yang tertuang dalam suatu working paper, Kenya ICT Action Network mendeskripsikan dengan sangat menarik mengenai kedudukan perempuan dan Cybercrime di Kenya sebagai berikut:

The use of cyber space and its attendant features of anonymity continue to influence both positively and negatively on social, economic, and political aspects of every society. Nevertheless, while the cyberspace have provided secure tools and spaces where woman can enjoy their freedom of expression, information and privacy of communication, the same benefits of anonymity and privacy also extended to those who employ ICTS (Information Communication and Technologies, penulis) for criminal activities and use the internet to commit violence against women. The use of mobile phones and internet to stalk, abuse, traffic, intimidate and humiliate women in palpable in developing countries including Kenya. The lack of specific cybercrime/cyber securities legislation makes it even more difficult to punish those who use ICTs tools to conduct violence against women. While, the review of the Kenya Communications Amandment Act enacted in January 2009, begins to deal with the problem, it does not explicitly deal wit all cybercrime and cyber security issues on the person and specifically women... (KICTAnet, 2010:1)

Lebih jauh dikemukakan oleh KICTAnet sebagai berikut:

The emergence of the ICTs provides an unrivalled opportunity for women to exploit their capabilities to improve their quality of life as well as the contribution for the welfare of the society.

Development of cyber security policy and legislation that recogniise the special needs of women and provides safe space for them to communicate freely and effectively to contribute to their second economic, political and cultural development.

The assumption is that while ICTs have contributed immensely to addressing gender inequalities they have also exacerbated existing structures of inequality by enabling cybercriminals to access and misuse them to abuse, harrass and volate women, and as a result continue to reinforce existing structures $f$ inequality.

Women's contribution to social economic, political and cultural development is therefore limited due to fear of virtual harassment, abuse, and violence. (KICTAnet, 2010:1)

Perkembangan kejahatan yang terkait dengan keberadaan teknologi muncul berbagai penamaan, kejahatan telematika, kejahatan mayantara, kejahatan siber, penyalahgunaan komputer, atau cyber crime. Sesuai dengan sifatnya, teknologi ini muncul dan menjelma menjadi kejahatan yang ber- 
sifat modern, kompleks, rumit, serta tidak mengenal batas waktu dan ruang (borderless). Keruwetan dan kompleksitas kejahatan modern yang dilahirkan karena kemajuan teknologi membawa satu konsekuensi di mana hukum, terutama hukum positif yang merupakan ciri hukum modern, makin jauh tertinggal dengan pesatnya perkembangan sosial yang dimunculkan oleh teknologi. Kekosongan hukum (Rechtsvacuum) ini memberikan kemudahan terjadinya kejahatan untuk berkembang pesat.

Perkembangan teknologi telah mempengaruhi pelbagai bidang kehidupan manusia, termasuk di dalamnya adalah memunculkan potensi kekerasan bagi perempuan dan anak. Dengan demikian menarik untuk dibahas dalam artikel ini adalah bagaimana pentingnya pendidikan berperan aktif di dalam mencegah timbulnya kekerasan pada perempuan dalam konteks perkembangan kejahatan siber.

\section{Metode Penelitian}

Penulisan artikel ini mempergunakan metode penelitian hukum yuridis normatif, yang ditunjang dengan data empiris. Penelitian hukum yuridis normatif ini mendasarkan pada adanya penelitian atas bahan kepustakaan, yaitu terkait dengan Undang Undang Nomor 11 Tahun 2008 tentang Informasi dan Transaksi Elektronik, Undang Undang Nomor 44 Tahun 2008 tentang Pornografi, UN Declaration on the Elimination of Violence Against Women, dan Convention on the Elimination of All Forms of Discrimination Against Women yang telah diratifikasi oleh Pemerintah Indonesia. Pada penelitian ini dipergunakan penalaran yang bersifat deduktif, dan dengan mendasarkan pada pendekatan yang bersifat konseptual (dengan merujuk pada konsep-konsep dan doktrin-doktrin yang ada), dan pendekatan berdasarkan perundang-undangan. Hasil penelitian diharapkan bersifat komprehensif dan dengan ditunjang adanya fakta-data empiris, khususnya terkait dengan perkembangan kejahatan siber yang berimplikasi pada munculnya kekerasan pada perempuan.

\section{Hasil dan Pembahasan}

\section{a. Macam-macam Kejahatan Siber dan Potential Victim}

Konggres PBB ke-X mengenai pencegahan kejahatan dan penanganan pelaku tindak pidana pada hakikatnya telah membahas isu mengenai kejahatan yang berhubungan dengan jaringan komputer. Cybercrime dibedakan dalam 2 kategori, yaitu pengertian cybercrime dalam arti sempit yang bermakna setiap perilaku ilegal yang ditujukan dengan sengaja pada operasi elektronik yang menargetkan sistem keamanan komputer dan data yang diproses oleh sistem komputer tersebut. Cybercrime dalam arti luas meliputi setiap perilaku ilegal yang dilakukan dengan maksud atau berhubungan dengan sistem komputer dan jaringan, termasuk kejahatan pemilikan, penawaran atau distribusi dari komputer sistem atau jaringan. (Golose, 2008: 25).

Petrus Golose menjelaskan "Cybercrime dapat diartikan sebagai kegiatan ilegal dengan perantara komputer yang dilakukan melalui jaringan elektronik global. Perbedaannya dengan kejahatan konvensional dapat dilihat dari kemampuan serbaguna yang ditampilkan akibat perkembangan informasi dan teknologi komunikasi yang semakin canggih". (Golose, 2008:25). Shinder, sebagaimana dikutip oleh Petrus Golose, menjelaskan lebih jauh mengenai pengertian kejahatan siber adalah perbuatan yang illegal di suatu negara belum tenty dianggap di negara lain" (Golose, 2008:25). V.D Dudeja menjelaskan kejahatan siber dalam dimensi sebagai berikut:

Cyber Crime is the most recent type of crime which effects many people. This is the biggest challenge for police, prosecutorts and lawmakers. If we do not wake up we would be mere spectators in the Cyberworld. The criminal provisions deal with the offences such as tempering with source code, hacking into computer systems, publishing of obscene information and misuse of licenses or digital signature. The problem is multifold in an area like pornography which has its basis, certain moral standards and uses parameters like indecency and obscenity. There are fluid depending upon 
social values. When this is coupled with the intangible transient medium that is the Internet, the result is enough to make legislators lament and magistrates mourn would be offences like hackling for which a computer and network is essential to the feasibility of the offence.

- Computer assisted crimes - Cyberporn where the mdeium is used to assist in some activity that is prohibited by law;

- Criminal activity where a computer is incidental e.g in a case of fraud, the evidence recording the transaction may be stored on a hard dsk and can be used as evidence (Dudeja, 2002: 9)

Dudeja mencoba menjelaskan dalam sebuah dimensi partisipasi teknologi informasi komunikasi, dan kompleksitas keanekaragaman macam perbuatan jahat yang muncul, dan akan terus menjadi sesuatu tantangan terbesar bagi penegak hukum, polisi, maupun jaksa. Manusia yang sesungguhnya menjadi pelaku dan target dari kejahatan tersebut apabila hanya terdiam dan tidak melakukan suatu upaya yang bersifat pencegahan dan pemberantasan bagi kejahatan siber sendiri akan menyebabkan kerugian bagi manusia sendiri. Berbagai macam kejahatan siber yang terus berkembang sesungguhnya menyentuh berbagai masalah moral, masalah hak hidup yang mendasar, salah satu yang terbesar adalah masalah yang berkaitan dengan pornografi dan permasalahan pelecehan seksual khususnya terhadap anak dan perempuan.

Russel G. Smith et al menjelaskan bahwasanya "The use of Internet and other networked services clearly makes such activities possible and creates jurisdictional questions about the most appropriate place in which legal proceedings should be brought". (Smith et al, 2004:12). Masalah cyber crime secara hakikat akan mengubah konsep mengenai jurisdiksi. Pasal 2 Undang Undang Nomor 11 Tahun 2008 tentang Informasi dan Transaksi Elektronik menganut prinsip berlaku di mana saja. Hal tersebut menunjukkan bahwasanya kejahatan siber dapat terjadi di mana saja, dilakukan oleh siapa saja, dan korbannya juga dapat meliputi siapa saja, termasuk di dalamnya adalah perempuan dan anak yang menjadi targeted victim atas perkembangan kejahatan siber ini.

Perkembangan targeted victim ini tidak lepas dari suatu pemahaman akan asal mula karakteristik kejahatan siber yang bersifat violence, tetapi kemudian bergeser menjadi bersifat violence. Mengenai hal ini, Shinder, sebagaimana dikutip oleh Petrus Golose, membedakan cyber crime dalam 2 dimensi yaitu kejahatan dengan kekerasan atau secara potensial mengandung kekerasan seperti: $c y-$ berterrorism, assault by threat, cyberstalking, dan child pornography. Di sisi lain adalah kejahatan siber tanpa kekerasan yang meliputi cybertrespass, cybertheft, destructive cybercrimes, and other non violent cybercrimes. (Golose, 2008:28). Pergeseran karakteristik kejahatan siber sendiri sesungguhnya akan menempatkan perempuan dan anak menjadi target kejahatan siber mengingat bentuk assault by threat, cyberstalking, ataupun pornography lebih memilih target korban berupa perempuan dan anak. Kejahatan siber dapat menimbulkan akibat luka fisik terhadap manusia, tetapi juga dapat meliputi akibat lainnya secara mental atau psikologi.

Wall, sebagaimana dikutip oleh Sutan Remy Sjahdeini, menjelaskan dari kategori cyber crime menjadi 4 kategori, yaitu:

1. Cyber trespass - crossing boundaries into other people's property and/olr causing damage, e.g hacking, defacement, viruses.

2. Cyber deceptions and thefts - stealing (money, property), e.g credit card fraud, intellectual property violations (a.k.a piracy)

3. Cyber pornography - breaching laws on obscenity abd decency

4. Cyber violence - doing psychological harm to, or inciting physics harm against others, thereby breaching laws relating to the protection of the persons, e.g hate speech, stalking (Sjahdeini, 2009:42)

Secara kategorisasi, dapat dipahami dari pendapat Yar, sebagaimana dikutip oleh Sutan Remy Sjahdeini, yaitu crimes against property; crimes against morality; crimes against the state. (Sjahdeini, 2009: 42). Makna yang lain yang dipahami adalah kejahatan 
siber pada hakikatnya adalah kejahatan atas harta benda (property), kejahatan atas orang (persons), dan kejahatan terhadap pemerintah (Government).

\section{b. Kekerasan Terhadap Perempuan dalam Konteks Kejahatan Siber}

Setiap manusia pada dasarnya memiliki hak asasi manusia yang tidak memandang jenis kelamin atau kedudukan sosial atau kecerdasan sosial. Semua sama di mata hukum. Menurut UNIFEM,

Hak asasi bertujuan menjamin martabat setiap orang. Hak asasi memberikan kekuatan moral untuk menjamin dan melindungi martabat manusia berdasarkan hukum, bukan atas dasar kehendak, keadaan, ataupun kecenderungan politik tertentu. Hak-hak dan kebebasan tersebut memiliki ciri-ciri berikut tidak dapat dicabut/dibatalkan (inalienable), universal, saling terkait satu sama lain (interconnected) dan tidak dapat dipisah-pisahkan (indivisible). Secara sederhana, dapat dikatakan bahwa setiap manusia memiliki sekaligus hak atas kebebasan, rasa aman, dan standar hidup yang layak (UNIFEM, 2004:11)

Memahami hal tersebut sesungguhnya tidak boleh dibeda-bedakan antara pemberian hak-hak baik kepada laki-laki ataupun perempuan, dewasa ataupun anak-anak, tua ataupun muda, dengan sebuah pemahaman bahwa hak-hak masing-masing adalah hak yang akan membentuk perlindungan secara utuh bagi pribadi-pribadi tersebut. Namun demikian yang terjadi seringkali muncul sebuah pembedaan perlakuan, secara khusus yang terjadi pada perempuan dan anak (dalam hal ini yang kemudian dibicarakan adalah kekerasan terhadap perempuan).

Terkait dengan masalah kebebasan berekspresi, Convention for the Protection of Human Rights and Fundamental Freedom 1950 menjadi salah satu dasar peletakan pemberian perlindungan atas kebebasan seseorang, termasuk di dalamnya adalah perempuan. Artikel 10 dari Convention for the Protection of Human Rights and Fundamental Freedom menentukan:

1. Everyone has the right to freedom of expression. The right shall include freedom to hold opinions and to receive and impart information and ideas without interference by public authority and regardless of frontiers. This article shall not prevent States from requiring the licensing of broadcasting, television or cinema enterprises.

2. The exercise of this freedoms, since it carries with it duties and responsibilities, may be subject to such fromalities, conditions, restrictions or penalties as are prescribed by law and are necessary in a democratic society, in the interest of national security, territorial integrity or public safety, for the prevention of disorder of crime, for the protection of health or morals, for the protection of the reputation or rights of others, for preventing the disclosureof informatioon received in confidence, or for maintaining the authority and impartiality of the judiciary

Berbagai pemikiran akan kebutuhan pentingnya mewujudkan perlindungan yang sama kepada perempuan dan anak mendominasi pemikiran internasional maupun domestik untuk mewujudkan pemberian perlindungan kepada perempuan atas kemungkinan dilakukannya kekerasan yang berbasis gender (Gender based violence) yang secara lebih khusus lagi adalah kekerasan terhadap perempuan (violence against women). Berbagai instrumen internasional dapat dipahami yang memberikan kerangka pemikiran pemberian perlindungan hukum kepada perempuan. Terkait dengan pembahasan di dalam artikel ini adalah Convention on the Elimination of All Forms of Discrimination Against Women 1979, Optional Protocol to the Convention on the Elimination of All Forms of Discrimination Against Women 1999, UN Declaration on the Elimination of Violence Against Women 1999.

UN Declaration on the Elimination of Violence Against Women dalam Artikel 1 menyatakan sebagai berikut:

For the purpose of this declaration, the term "violence against women" means any act of gender based violence that results in, or likely to result in, physical, sexual or psychological harm or suffering to women, 
including threats of such acts, coersion or arbitrary deprivations of liberty, whether occurring in public or private life

Berdasarkan definisi tersebut dipahami pada hakikatnya kekerasan terhadap perempuan dapat berupa tindakan apapun, baik yang berdasarkan pembedaan jenis kelamin yang berakibat atau mungkin berakibat timbulnya kesengsaraan atau penderitaan perempuan secara fisik, seksual, psikologis, termasuk ancaman, pemaksaan, atau perampasan kemerdekaan secara sewenangwenang. Amarsanaa Darinsuren menegaskan bahwasanya Gender Based Violence tidak identik dengan Violence Against Women, karena pada hakikatnya Violence Against Women hanya merupakan salah satu bentuk dari Gender Based Violence. (Darinsuren, 2011:6).

Ketentuan Pasal 2 Deklarasi Penghapusan Kekerasan Terhadap Perempuan tersebut menjelaskan:

Kekerasan terhadap perempuan harus dipahami mencakup, tetapi tidak terbatas pada, hal-hal sebagai berikut:

1. Tindak kekerasan secara fisik, seksual dan psikologis terjadi dalam keluarga, termasuk pemukulan, penyalahgunaan seksual atas anak-anak perempuan dalam keluarga, kekerasan yang berhubungan dengan mas kawin, perkosaan dalam perkawinan, pengrusakan alat kelamin perempuan dan praktek-praktek kekejaman tradisional lain terhadap perempuan, kekerasan di luar hubungan suami istri dan kekerasan yang berhubungan dengan eksploitasi;

2. Kekerasan secara fisik, seksual dan psikologis yang terjadi dalam masyarakat luas, termasuk perkosaan, penyalahgunaan seksual, pelecehan dan ancaman seksual di tempat kerja, dalam lembaga-lembaga pendidikan dan di manapun juga, perdagangan perempuan dan pelacuran paksa

3. Kekerasan secara fisik, seksual dan psikologis yang dilakukan atau diabaikan oleh Negara, di manapun terjadinya. (Pusat Kajian Wanita dan Gender, 2004: 66-67)

Perkembangan teknologi informasi dan komunikasi pada hakikatnya tidak dapat ditolak, dan selalu akan terus memacu setiap orang, termasuk di dalamnya adalah perempuan dan anak, yang seharusnya juga mendapatkan kesempatan yang sama untuk menikmati fasilitas yang diberikan oleh Internet. Perempuan berhak untuk mengadakan komunikasi dengan melalui media-media sosial, situs pertemanan, bahkan dengan mendapatkan keuntungan ekonomi dengan cara berjualan secara online, dsb. Namun demikian tidak dipungkiri bahwa ancaman-ancaman yang muncul sebagai sisi negatif perkembangan teknologi informasi dan komunikasi tersebut juga menempatkan perempuan pada posisi rentan atas perbuatan kekerasan yang mungkin terjadi. Dengan demikian bentuk kekerasan terhadap perempuan sebagaimana dimaksudkan dalam Deklarasi tersebut dapat pula telah mengalami perkembangan, khususnya ketika dipahami cara-cara terjadinya kekerasan terhadap perempuan.

Terkait dengan perkembangan Teknologi Informasi dan Komunikasi dalam hubungannya dengan munculnya kekerasan terhadap perempuan dengan varian lain, dapat dijelaskan bahwa sifat anonimity dari internet sendiri menjadi salah satu sumber penting pemicu terjadinya kekerasan terhadap perempuan. Selain itu tereksplotasinya perkembangan informasi teknologi menjadi suatu kejahatan, tentunya diikuti oleh keinginan-keinginan pelaku kejahatan untuk mengambil keuntungan baik yang bersifat finansial maupun non finansial, yang kemudian dimanifestasikan dalam berbagai bentuk penyimpangan, yang akhirnya memunculkan perspektif kekerasan terhadap perempuan, baik fisik, seksual dan psikologis dalam dimensi yang baru.

Perkembang teknologi informasi dan komunikasi yang kemudian terwujud dalam sebuah bentuk teknologi Internet menjadi hak bagi setiap orang untuk menikmatinya, termasuk di dalamnya adalah perempuan dan anak. Ketentuan Pasal 3 Deklarasi Penghapusan Kekerasan Terhadap Perempuan menjelaskan:

Perempuan berhak untuk menikmati dan memperoleh perlindungan hak azasi manusia dan kebebasan azasi yang sama da- 
lam bidang politik, ekonomi, sosial, budaya, sipil atau bidang-bidang lainnya. Hak-hak tersebut termasuk, antara lain:

1. Hak atas kehidupan

2. Hak atas persamaan

3. Hak atas kemerdekaan dan keamanan pribadi

4. Hak atas perlindungan yang sama berdasar hukum

5. Hak untuk bebas dari segala bentuk diskriminasi

6. Hak untuk mendapatkan pelayanan kesehatan fisik maupun mental yang sebaikbaiknya

7. Hak atas pekerjaan yang layak dan kondisi kerja yang baik

8. Hal untuk tidak mengalami penganiayaan atau kekejaman lain, perlakuan dan penyiksaan secara tidak manusiawi atau sewenang-wenang. (Pusat Kajian Wanita dan Gender, 2004: 67-68)

Membahas mengenai kekerasan terhadap perempuan, tentu saja membutuhkan sebuah kerangka perlindungan atas perempuan. Khusus yang terkait dengan perkembangan kejahatan siber, maka harus berpikir dengan konteks yang mengikuti makna kekinian atas perlindungan tersebut.

Convention on the Elimination of All Forms of Discrimination Against Women (CEDAW) 1979 kemudian diratifikasi oleh Indonesia, dan disebut sebagai Konvensi Penghapusan Segala Bentuk Diskriminasi Terhadap Perempuan, merupakan konvensi yang berupaya untuk meletakkan standar umum ke dalam suatu kontekstual pada kelompok khusus, dalam hal ini adalah perempuan. Namun demikian tidak dapat dinyatakan secara mutatis mutandis bahwasanya CEDAW hanya berupaya untuk memberikan perlindungan kepada perempuan semata-mata mengingat banyaknya pelanggaran terhadap hak asasi perempuan, tetapi harus dimaknakan bahwa hak perempuan secara khusus muncul di tengah-tengah pemahaman mengenai hak asasi manusia secara umum. Menjadi suatu hal yang kemudian dapat memperkaya pemahaman hak asasi itu sendiri. jelaskan:

CEDAW dalam pembukaannya men-
Regarding that discrimination against women violates principles of equality of rights and respect for human dignity, is an obstacle to the participation of women, on equal terms with men, in the political, social, economic and cultural life of their countries, hampers the growth of the pros perity of society and the family and makes more difficult the full development of the potentialities of women in the service of their countries and if humanity.

Masalah kekerasan yang terjadi pada perempuan mewarnai perbincangan seharihari, di mana sesungguhnya terdapat perbedaan perlakuan yang nyata terjadi. Artikel 1 CEDAW memberikan definisi mengenai diskriminasi terhadap perempuan sebagai berikut

'discrimination against women' shall mean any distinction, exclusion or restriction made on the basis of sex which has the effect or purpose of impairing ir nullifying the recognition, enjoyment or exercise by women, irrespective of their marital status, on a basis of equality of men and women, of human rights and fundamental freedoms in the political, economic, social, cultural, civil or any other field

Demikian pula dengan perkembangan dimensi kejahatan siber yang rupanya dapat memunculkan masalah atas kekerasan terhadap perempuan.

Salah satu jenis kekerasan terhadap perempuan dewasa ini berkembang karena perkembangan teknologi informasi dan komunikasi yang kemudian menjelma menjadi kejahatan siber. Sebelumnya telah dijelaskan bahwasannya jenis kejahatan siber yang muncul semakin berkembang, dan pada akhirnya menyentuh pada suatu keadaan di mana kejahatan siber dilakukan dengan kekerasan sebagaimana dikemukakan oleh Shinder, misalnya cyberstalking, pornography dan lebih khusus adalah mengenai cyber pornography, mengunggah foto-foto dari perempuan-perempuan, bahkan yang telah dimanipulasi fotonya sehingga nampak seperti asli dan berada dalam keadaan telanjang, atau pelecehan melalui email, sms, ataupun me- 
lalui percakapan di chat room, penghinaan. Sebuah website about.com dalam penjelasannya menyatakan sebuah fakta dan statistik tentang Cyberstalking dan Perempuan di tahun 2009 sebagai berikut:

More than one million women and 370.000 men are stalked annually in the United States. An astonishing one in twelve women and one in forty-five men will be stalked in their lifetime. The average duration of stalking is nearly two years and even longer if the stalking involves intimatge partners Within the past twelve months, 9.3 million Americans were victims of identity theft. Identity theft is often present in situations of domestic abuse and can become a form of economic abuse once the woman has left her partner. One and a half million of those reporting identity theft in 2004 also reported that they suffered from domestic abuse and harassment from their exes. These latter stats could be more correctly recatagorized as cyberstalking incidents.

$\ldots$

The Department of Justice statistical report of June 26, 2006 indicates that, on average, more than three women are murdered by their husbands or boyfriends in this country everyday. The FBI reports that domestic violence is leading cause of injury to women between the ages of 15 to 44 - more than car accidents, muggings, and rapes combined. Cyberstalking probvides astonishingly easy and cheap tools for an abuser to locate women who have tried away or go into hiding. (http://womenissues.about. com, 2009)

Sebagaimana dijelaskan pada awal pembahasan, bahwasannya dalam dunia siber tidak dapat dipilih apakah yang akan menjadi korban adalah harus perempuan ataukah laki-laki, orang dewasa ataukah anak-anak, ataukah lainnya. Namun demikian harus disadari pula bahwasannya posisi perempuan dan anak adalah rentan terhadap hal-hal tersebut, di mana yang biasanya menjadi abuse victims adalah perempuan dan anak-anak. Melalui survey di atas dapat dipahami sebuah kondisi yang sangat mungkin terjadi, yaitu bahwa cyberstalking kadang bermula dari adanya rape yang pastinya dilakukan oleh laki-laki kepada perempuan (dewasa maupun anak), kekerasan di dalam pacaran (setelah putus pacaran maka foto atau informasi lainnya yang bersifat privasi (foto mesra dan sarat ketidakpantasan) akan disebarkan melalui media elektronik yang tujuannya untuk mengancam ataupun menakut-nakuti bekas pacarnya tersebut), dapat juga kekerasan dalam rumah tangga yang dilakukan suami terhadap istri, ataupun dilakukan oleh pasangan yang bercerai, yang dapat diberikan ancaman, dll. Yang menyedihkan adalah perempuan-perempuan tersebut (pacar, mantan pacar, istri, mantan istri) tidak mengetahui partner yang ditemui di chat room adalah pasangannya atau mantan pasangannya. Chat room benar-benar menjadi suatu media yang bersifat anonim. Perempuan berada dalam sebuah kondisi yang harus dilindungi dari segala bentuk kekerasan.

Cyberstalking pada hakikatnya masuk dalam sebuah manifestasi kejahatan siber atas privasi. Yang dimaksud dengan Cyberstalking dijelaskan oleh Sutan Remy Sjahdeini sebagai berikut:

Cyberstalking berasal dari dua kata, yaitu "cyber" dan "Stalking". Arti "cyber" telah diketahui... Arti yuridis dari "stalking" adalah "harass somebody persistently: to harass somebody by persistent, inappropriate, and unwanted attention, e.g. by constantly following, telephoning, e-mailing, or writing to him or her...

Dari arti stalking tersebut di atas, gangguan baru dapat dikatakan sebagai stalking hanya apabila gangguan tgersebut dilakukan terus-menerus atau tidak henti-hentinya dengan melakukan perbuatan-perbuatan yang tidak diinginkan oleh pihak yang diganggu. Misalnya mengikuti, menelpon, mengirim email, mengirim surat kepada seseorang secara terus-menerus...

Cyberstalking memuat mengenai masalah "harassment" dan "threaten", yang muncul kemudian menjadi perbuatan yang mengganggu dan mengancam. Berbagai literatur sering menggunakan istilah cyberstalking secara berganti-gantian dengan cyberharassment, dan sering tertukar. Cara-cara yang dilakukan adalah dengan mengirimkan junk 
email kepada beberapa alamat email sekaligus, atau bahkan sengaja ditujukan kepada seseorang yang dimaksud. Tidak jarang yang menjadi targeted victim adalah anggota keluarganya tersendiri, ataupun teman-teman dan sahabat-sahabat dekat, rekan kerja, dan bahkan dari lingkungannya sendiri Sutan Remy Sjahdeini, mengutip pendapat dari Wayne Petherick, menjelaskan mengenai perbedaan pandangan bagaimana cyber stalking itu disyaratkan dapat terjadi, yaitu sebagai berikut:

Kebanyakan hukum yang mengatur mengenai stalking mensyaratkan bahwa suatu perbuatan baru dapat disebut sebagai kejahatan stalking apabila pelaku melakukan ancaman terhadap korban (a credible threat of violence against the victim). Adapula hukum yang menentukan bahwa melakukan ancaman terhadap keluarga dekat dari korban juga termasuk kejahatan stalking (threat against the victim's immediate family). Adapula hukum yang menentukan bahwa suatu perbuatan hanya dianggap merupakan kejahatan stalking apabila dalam melakukan perbuatan itu pelaku melakukan ancaman. Sementara dalam hukum yang menganggap suatu perbuatan adalah illegal stalking cukuplah apabila perbuatan tersebut berupa perbuatan yang menjengkelkan (annoying) atau yang bersifat intimidasi. (Sjahdeini, 2009:95)

Petrus Golose menjelaskan mengenai cyberstalking, yang dimaknakan sebagai penguntitan di Internet, yaitu: "Pelecehan seksual melalui internet yang menciptakan ketidaknyamanan dapat berkembang menjadi ancaman fisik dan menciptakan trauma mendalam pada diri korban. Ancaman tersebut dapat meningkat menjadi penguntitan $d$ dunia nyata dan perilaku kekerasan".

Dengan demikian dapat dipahami dan kemudian disepakati bahwa bentuk kekerasan tidak dapat dibatasi dengan hanya sebuah makna harus terjadi suatu perbuatan yang bersifat pengancaman belaka, tetapi harus pula melingkupi perbuatan-perbuatan yang bersifat mengganggu sehingga orang yang diganggu merasa terancam dan terusik. Sekalipun dampak yang terjadi bukanlah berupa akibat fisik yang terganggu, tetapi karena dilakukannya melalui suatu media elektronik, maka sesungguhnya dipahami bahwa akibat yang muncul adalah menyangkut gangguan psikis, psikologis, mental.

Cyberstalking tidak dapat dibatasi hanya terjadi pada perempuan dan anak yang terjadi di suatu tempat saja, tetapi mengingat sifatnya yang anonim, maka kekerasan ini dapat terjadi di mana saja. Tidak terkecuali di Indonesia. Menurut data yang diambil dari detiknews di tahun 2011, Polda Metro Jaya menerima 300 laporan kejahatan Cyber, dan kebanyakan adalah kasus penipuan, penghinaan atau pencemaran nama baik di Facebook. Selain itu dijelaskan bahwa Perempuan dan anak merupakan pihak yang lebih rentan menjadi korban kejahatan siber ini, baik yang di perkotaan bahkan di pedesaan. Perempuan dan anak posisinya mudah dipengaruhi secara psikologis. (Sumber: detiknews, diunduh pada 26 September 2013). Salah satu kasus yang terjadi adalah seperti apa yang diberitakan oleh salah satu media massa, yaitu poskota.co.id, dimuat berita sebagai berikut:

BOGOR: Di Hina DI Facebook, Seorang Wanita Lapor Polisi

Lapor Polisi Karena Dihina Di Facebook BOGOR - Tidak terima kata-kata kasar dalam Facebook yang dikirim rekannya, seorang warga mengadu ke Mapolresta Bogor. Dalam laporannya bernomor LP/829/ $\mathrm{VI} / 2009 / \mathrm{SPK}$ tertanggal 23 Juni lalu ini, korban mengaku, telah direndahkan martabat dan harga dirinya.

Menurut Fely, isi facebook itu merupakan penghinaan besar. Pasalnya dalam kata-kata di facebook, pelaku, Ujang Romasnyah menghinanya dengan ucapan gendut, jelek, dan lain sebagainya yang dinilais angat merendahkan karena menyebut berbagai nama binatang.

Korban menunjukan tulisan di Facebooknya " Hai ....., lu ngga usah ikut campur. Gendut, kaye tante2, ngga bs gaya. Emang lu siapa. Urus aja diri lu kaya....... So cantik, ga bs gaya. Belagu. Nyokap lu ngga sanggup beliin baju buat gaya ya, makanya lu punya gaya gendut, .... besar lu, kaya lu yg bagusaja. Emang lu siapanya UJ. Hai gendut.".

Kasat Reskrim Polresta Bogor, AKP Ir- 
wansyah mengungkapkan, kasus pencemaran nama baik mirip kasus Prita di Tangerang, kini sedang dalam penyilidikan. Keterangan saksi korban dan saksi lainnya sudah rampung. "Kami akan memanggil pelaku, guna dimintai keterangan. Jika terbukti, maka ancaman pidanya sudah disiapkan," tandas Irwansyah. (poskota.co.id, diunduh pada 26 September 2013)

Kasus lainnya yang dapat dijadikan sebagai bahan perenungan untuk upaya memberikan edukasi kepada masyarakat adalah kasus yang diambil dari Media elektronik Tempo sebagai berikut:

\section{BANDAR LAMPUNG: PNS LAPORKAN} PNS KE POLISI KARENA FACEBOOK Dihina di Facebook, Pegawai Negeri Sipil Lapor Polisi

Kamis, 02 Juli 2009 | 18:30 WIB

TEMPO Interaktif, Bandar Lampung - Merasa dihina di situs jejaring pertemanan, Facebook, seorang pegawai negeri sipil bernama Verona Bertha, 40 tahun, melaporkan rekan kerjanya ke polisi. Dia mengaku merasa malu karena mendapat caci maki di situs tersebut. "Saya merasa shock karena kata-kata kasar itu dibaca banyak orang di internet," kata Verona Bertha, seusai melapor kasus itu ke Unit Pelayanan Perempuan dan Anak Kepolisian Kota Besar Bandar Lampung, Kamis (02/07).

Pegawai negeri sipil yang bertugas di Dinas Kehutanan Propinsi Lampung itu mengatakan saat membuka situs Facebook miliknya, mendapati kalimat kasar bernada cacian di situs jejaring pertemanan itu. Dia menduga penghinaan di Facebook itu karena pengirim bernama Muhammad Iqbal merasa iri dengan karirnya. "Tapi saya belum yakin itu sebab tidak ada tanda-tanda perselisihan di ruang kerja. Semuanya normal-normal saja," katanya.

Di halaman pesan Facebook miliknya, Muhammad Iqbal mempublikasikan kata-kata kotor dan caci maki yang ditujukan ke Verona. Dari kalimat itu, Muhammad Iqbal kesal karena Verona mendapat promosi di kantornya. Sayangnya, Muhammad Iqbal tidak bisa dihubungi untuk dikonfirmasi. Sementara itu Komisaris Polisi Namora Simanjutak, Kepala Satuan Reserse dan Kri- minal Poltabes Bandar Lampung berjanji akan menindak lanjuti laporan tersebut. Namora mengatakan pihaknya akan segera memeriksa terlapor yang telah menyebarkan penghinaan di internet. "Terlapor atau si pengirim pesan yang berbau menghina itu akan segera kami periksa," katanya.

Polisi menyatakan penyebar kata-kata tidak menyenangkan itu akan dijerat dengan Pasal 310, Kitab Undang-undang Hukum Pidana tentang Penghinaan. "Jika pengirim pesan itu akan diancam dengan hukuman 9 bulan penjara," ujarnya. sumber: tempo (tempo.co.id diunduh terakhir pada 26 September 2013)

Melalui kasus-kasus di atas dapat dipahami bahwasannya cyberstalking menjadi permasalahan penting di samping masalahmasalah lainnya terkait dengan kejahatan siber yang muncul. Perempuan menjadi pihak yang berpotensi rentan menjadi korban cyberstalking.

Masalah cyberstalking tidak hanya membahas mengenai perbuatan psikis saja, tetapi juga diikuti dengan perbuatan fisik. Perbuatan domestic violence dapat bermula dari adanya upaya penguntitan yang dilakukan oleh suami atau pasangannya di Internet yang kemudian diikuti dengan kekerasan yang terjadi di dunia nyata, yang jelas menimbulkan suatu tindakan kekerasan terhadap perempuan, dan akhirnya menimbulkan korban nyata.

Jenis kejahatan siber lainnya yang juga seringkali menempatkan perempuan dan anak menjadi korban adalah kasus yang berhubungan dengan pelanggaran kesusilaan, yang berupa cyberpornography ataupun secara khsusu cyber child pornography (walaupun yang telah menjadi kesepakatan internasional, yang dilarang adalah childpornography). Sebagaimana diketahui masalah pornografi di internet sudah menjadi masalah yang serius yang harus ditangani oleh penegak hukum. Korban yang biasanya perempuan dan anak kadangkala tidak mengetahui bahwa dirinya menjadi korban kejahilan, keisengan, maupun kejahatan dari orang-orang tertentu yang memanfaatkan untuk mengeruk keuntungan pribadi ataupun alasan demi kesenangan belaka. 
Secara yuridis, Undang Undang Nomor 44 Tahun 2008 tentang Pornografi, pada Pasal 1 angka 1, menjelaskan bahwa yang dimaksud dengan pornografi adalah:

Pornografi adalah gambar, sketsa, ilustrasi, foto, tulisan, suara, bunyi, gambar bergerak, kartun, percakapan, gerak tubuh atau bentuk pesan lainnya melalui berbagai bentuk media komunikasi dan/atau perbuatan pertunjukan di muka umum, yang memuat kecabulan atau eksploitasi seksual yang melanggar norma kesusilaan, dalam masyarakat.

Penjelasan di atas menunjukkan mengenai pornografi, yang mana makna cyberpornography telah dijelaskan pula karena termasuk di dalam definisi tersebut karena pornografi itu dapat dlakukan dengan berbagai media komunikasi, yang di dalamnya termasuk internet atau media online lainnya.

Secara khusus, yang dimaksud dengan child pornography tidak dijelaskan oleh pembentuk Undang Undang Nomor 44 Tahun 2008 secara eksplisit, hanya terkandung di dalam perbuatan yang dilarang oleh Undang-undang, yaitu sebagaimana yang dicantumkan dalam ketentuan Pasal 4 ayat (1) huruf f. Demikian pula dengan Undang Undang Nomor 23 Tahun 2002 yang tidak memaksudkan mengenai pornografi anak. Mengenai pornografi anak ini dapat dijelaskan dari beberapa pendapat, antara lain yang dikemukakan oleh Petrus Golose, mengutip pendapat Shinder, yaitu:

Pornografi anak pada umumnya dikelompokkan sebagai kejahatan dengan kekerasan, walaupun beberapa pihak yang terlibat tidak melakukan kontak fisik dengan anak-anak yang menjadi objek kejahatan ini. Ini adalah suatu bentuk kejahatan karena kekerasan seksual terhadap anakanak dilakukan untuk menghasilkan materi pornografi dan karena orang-orang yang tertarik melihat materi-materi ini sering tidak cukup membatasi ketertarikan mereka hanya pada gambar-gambar dan khayalan saja akan tetapi juga melakukannya secara nyata seperti pedofilia. (Golose, 2008:34)

Penjelasan di atas cukup memberikan gambaran bahwasannya kekerasan terhadap korban anak akan sangat-sangat merugikan masa depannya. Pornografi anak tidak saja mengancam psikis anak, tetapi berbahaya apabila kemudian diikuti dengan perbuatan nyata sehingga menyebabkan kekerasan fisik kepada anak. Demikian pula yang terjadi pada masalah pornografi bagi orang dewasa, tidak jarang perempuan-perempuan yang terekspos di media internet, akhirnya menjadi incaran untuk dilakukannya kekerasan fisik, di samping secara mental psikologis, perempuan-perempuan tersebut telah menjadi korban, baik karena ketidaktahuannya maupun hal lainnya.

Di lain pihak, Sutan Remy Sjahdeini menjelaskan mengenai pornografi anak sebagai berikut:

Pornografi anak atau child pornography atau child porn adalah bahan-bahan porno (cabul) yang menampilkan anak-anak. Kebanyakan negara menyebutkan hal itu sebagai bentuk dari child sexual abuse dan merupakan hal yang melanggar hukum. Di mana child pornography berupa foto-foto yang menampilkan anak-anak yang terlibat dalam perilaku seksual dan memproduski bahan-bahan tersebut dengan sendirinya dilarang oleh hukum sebagai child sexual abuse di kebanyakan negara. (Sjahdeini, 2009:176)

Lebih luas lagi akhirnya yang berkembang dewasa ini adalah yang disebut dengan Internet Sexual Abuse, yang tidak hanya terjadi bagi anak, tetapi juga bagi dewasa khususnya perempuan. Berbagai kasus mengenai cyberpornography ini tidak dapat diuraikan satu per satu mengingat banyaknya jumlah kasus yang terjadi, misalnya pemuatan foto-foto dan video yang bersifat melanggar norma-norma yang bermuatan kesusilaan di berbagai website dan blog, media social network yang akhirnya mengarah pada masalah eksploitasi seksual dan ekonomi, ataupun trafficking, dan lain-lain.

Berbagai kasus yang dijelaskan sebagai contoh di atas sesungguhnya menunjukkan keprihatian bersama untuk memberikan perlindungan bagi perempuan dan anak, khususnya yang sangat terkait dengan masalah 
kekerasan terhadap perempuan yang terjadi sebagai perkembangan dunia informasi dan elektronik, melalui kejahatan sibernya. Contoh tersebut tidak terbatas pada cyberstalking dan cyberpornography saja, tetapi banyak pula menyangkut jenis kejahatan lainnya.

\section{c. Masalah Edukasi Pencegahan Ke- kerasan Terhadap Perempuan}

Pemerintah melalui Undang Undang Nomor 11 Tahun 2008 tentang Informasi dan Transaksi Elektronik (selanjutnya disebut sebagai UU ITE) telah berupaya untuk merespon perkembangan jaman melalui perkembangan teknologi informasi dan komunikasinya, sekaligus atas dinamika perkembangan kejahatan sibernya. Hal tersebut dapat dilihat dari konsiderans menimbang pada UU ITE. Sangat disadari oleh pemerintah bahwasanya Pemanfaatan Teknologi Informasi, media dan komunikasi telah mengubah baik perilaku masyarakat maupun peradaban manusia secara global. Perkembangan teknologi informasi dan komunikasi telah menyebabkan hubungan dunia menjadi tanpa batas (borderless) dan menyebabkan perubahan sosial, ekonomi, dan budaya secara signifikan. Teknologi informasi ternyata menjadi pedang bermata dua karena selain memberikan kontribusi bagi peningkatan kesejahteaan, kemajuan, dan peradaban manusia, sekaligus menjadi sarana efektif melawan hukum. (vide Penjelasan Umum UU ITE).

Perkembangan tersebut tentu saja tidak dapat dilepaskan pada masalah pentingnya memberikan perhatian pada sisi keamanan dan kepastian hukum dalam pemanfaatan teknologi informasi agar dapat berkembang secara optimal. Permasalahan di dunia siber tidak hanya terbatas pada masalah teknis, tetapi secara integral bermakna harus ada peninjauan dan penguatan aspekaspek lainnya, yaitu aspek hukum, teknologi, sosial, budaya, dan etika. (vide Penjelasan Umum UU ITE).

Asas-asas yang melandasi UU ITE adalah sebagaimana yang tercantum dalam ketentuan Pasal 3 UU ITE, yaitu Asas kepastian hukum, manfaat, kehati-hatian, itikad baik, dan kebebasan memilih teknologi atau netral teknologi. Berdasarkan penjelasan ter- sebut dapat dimengerti bahwa melakukan kegiatan atau perbuatan-perbuatan melalui dunia maya, membutuhkan keseluruhan asas tersebut, khususnya ketika berkaitan dengan permasalahan kejahatan siber. Orang harus dilindungi oleh hukum, dan tidak boleh menjadi target dari kejahatan. Oleh karenanya pemerintah berusaha memberikan perlindungan yang semaksimal mungkin sebagai upaya pencegahan maupun penegakannya. Namun demikian ternyata belum seluruhnya maksimal upaya-upaya tersebut.

Sebagai upaya yang dilakukan oleh Pemerintah Indonesia untuk memberikan perlindungan, maka UU ITE telah mengkriminalisasikan perbuatan-perbuatan Orang yang dapat menimbulkan kerugian bagi pihak lain. Hal tersebut sebagaimana termaktub di dalam ketentuan Pasal 27 sampai dengan Pasal 37. Khusus terkait dengan makalah ini, adalah yang terkait dengan masalah-masalah manifestasi kejahatan siber yang berbentuk pelanggaran privasi dan ketertiban umum. Lebih spesifik lagi dimaksudkan pada macam kekerasan terhadap perempuan. Ketentuan Pasal 27 ayat (1) UU ITE menentukan: "Setiap Orang dengan sengaja dan tanpa hak mendistribusikan, dan/atau mentransmisikan dan/atau membuat dapat diaksesnya Informasi Elektronik dan/atau Dokumen Elektronik yang memiliki muatan yang melanggar kesusilaan".

Ketentuan Pasal 27 ayat (1) UU ITE tersebut mensyaratkan pada adanya unsur subjektif tindak pidana yang berupa bentuk kesengajaan dan tanpa hak. Unsur memiliki muataun yang melanggar kesusilaan menjadi unsur penentu bahwasannya pelaku dapat dikenakan ketentuan Pasal 27 ayat (1) dalam sebuah muatan informasi elektronik dan/atau dokumen elektronik dengan muatan melanggar kesusilaan. Ukuran kesusilaan di sini dapat mengacu dari berbagai sumber hukum yang ada dan berlaku di Indonesia.

Ketentuan Pasal 27 ayat (3) UU ITE menentukan "setiap Orang dengan sengaja dan tanpa hak mendistribusikan dan/atau mentransmisikan dan/atau membuat dapat diaksesnya Informasi Elektronik dan/atau Dokumen Elektronik yang memiliki muatan penghinaan dan/atau pencemaran nama 
baik". Di sisi lain adalah Pasal 27 ayat (4) UU ITE yang menentukan "Setiap Orang dengan sengaja dan tanpa hak mendistribusikan dan/ atau mentransmisikan dan/atau membuat dapat diaksesnya Informasi Elektronik dan/atau Dokumen Elektronik yang memiliki muatan pemerasan dan/atau pengancaman". Lebih lanjut Pasal 29 UU ITE menjelaskan larangan "Setiap Orang dengan sengaja dan tanpa hak mengirimkan Informasi Elektronik yang berisi ancaman kekerasan atau menakut-nakuti yang ditujukan secara pribadi".

Setiap Orang yang melakukan perbuatan-perbuatan yang dilarang oleh UU ITE tersebut, yang apabila telah dapat dipertanggungjawabkan secara pidana, maka dapat dijatuhi sanksi pidana berdasarkan ketentuan Pidana yang ada di dalam UU ITE, yaitu pada Pasal 45 - Pasal 51, dan pemberatan yang dapat dijatuhkan diatur dalam Pasal 52, dengan pemberatan sanksi pidana sebesar $1 / 3$ dan 2/3 dari ancaman pidana pokoknya.

Melalui Pasal 40 UU ITE berusaha memberikan upaya pencegahan kejahatan melalui pengaturan akan Peran Pemerintah dan Peran Masyarakat, yang diharapkan dapat pula mencegah munculnya kekerasan terhadap perempuan karena perkembangan teknologi informasi dan komunikasi tersebut.

Mengingat masalah perkembangan teknologi informasi dan komunikasi yang melahirkan banyak perbuatan hukum dalam dimensi baru, membutuhkan suatu perhatian khusus pula. Permasalahan kejahatan siber merupakan suatu permasalahan tersendiri, yang tidak seluruhnya masyarakat memahami arti tersebut, walaupun mungkin masyarakat sendiri sudah terlibat aktif di dalam pemanfaatan Informasi Teknologi dan Komunikasi tersebut. Namun tetap harus diberikan pendidikan bagi semua orang, yang secara khusus juga diperhatikan adalah pada perempuan atas kerentanan terjadinya Violence Against Women dalam kejahatan siber. Masalah edukasi perlu diberikan kepada perempuan, di samping diperlukannya upaya-upaya penelitian dan pengumpulan data, agar kekerasan terhadap perempuan tidak terjadi, yang khususnya berkaitan dengan konteks kejahatan siber. Selain itu perempuan-perempuan Indonesia perlu disadarkan (awareness) agar tetap memperhatikan keamanan di dalam melakukan kegiatan-kegiatannya untuk memenuhi haknya di dalam mendapatkan informasi atau sekedar untuk tetap eksis di dunia social network.

Masalah edukasi atas upaya-upaya perlindungan diri sendiri (self protection) perlu dijelaskan kepada perempuan-perempuan di Indonesia agar tidak menempatkan perempuan menjadi korban kekerasan yang mungkin terjadi pada dirinya. Pada masalah self protection ini, masyarakat perlu disadarkan untuk tidak meletakkan seluruh informasi yang sifatnya privat ke dalam media jejaring sosialnya, atau sekedar berhati-hati dengan cara tidak menerima segala macam pertemanan yang ditawarkan oleh orang-orang yang tidak dikenal sebelumnya, tidak memberikan informasi kartu kredit ataukah hal lainnya, tidak mudah mengunggah foto-foto pribadi khususnya yang bersifat privacy (baik pada media jejaring sosial, ataupun instant messengers, dan lain-lain), tidak mudah meng-up date status terkait keberadaan diri sendiri, misalnya apakah sedang di rumah sendirian, ataukah sedang berada di suatu lokasi tertentu, dll. Dengan demikian diharapkan melalui Women's self awareness and self protection ini dapat menjadi salah satu pilar yang akan mencegah para perempuan untuk mengalami kekerasan dalam bentuk apapun. Hal tersebut termasuk pula dengan upaya untuk mengubah suatu cara berpikir dari (the way of thinking) para perempuan yang kemudian akan membantu cara berpikir laki-laki untuk tidak menempatkan para perempuan pada posisi rentan mengalami kekerasan karena perkembangan dunia maya ini. Terkait hal ini, Maria Chin Abdullah dari Persatuan Kesedaran Komuniti Selangor (EMPOWER) menjelaskan:

Cyber-violence is an extension of existing and often, entrenched attitudes in society towards women - not just men's attitudes towards women but also women's attitudes to their own sex...

To effectively tackle cyber-violence, society must deal with the issue of domestic violence against women as a whole... stressed the need to educate society on creating awareness and increasing gender 
sensitisation efforts, especially among men, as most perpetrators of domestic VAW are male.

Women must also know their rights, be willing to take a stand for them and hold society up to basic standards of those rights... No laws can really cover that. It's really about your thinking. We haven't done enough in that area - to educate young people, particularly boys, about what you mean by respecting women. And also girls - young girls who feel they want to have a good time and hang around with reasonably rich people and go to the nice places like hotels - but they are dangerous. You have to know the consequences when you behave in a particular manner (Sumber http:// www.theborneopost.com, 2011)

Memahami kejahatan siber dalam segala manifestasinya yang kemudian dapat memunculkan kekerasan terhadap perempuan memerlukan upaya edukasi yang sangat kuat mengingat banyaknya perbuatan hukum baru yang muncul dalam perkembangan teknologi informasi itu sendiri, berikut dengan akibat-akibat hukumnya.

Bentuk edukasi lainnya yang perlu diberikan adalah mengenai pentingnya pelaporan atas setiap peristiwa kekerasan terhadap perempuan yang dialaminya sendiri atau dialami oleh orang lain agar dapat diupayakan upaya pencegahannya. Untuk ini perlu dipikirkan kontribusi dari organisasi yang peduli dengan masalah penanganan masalah kekerasan terhadap perempuan tersebut untuk menyediakan suatu sarana pelaporan, selain tentunya melaporkan kepada Pihak Kepolisian.

\section{Simpulan}

Berbagai langkah edukasi perlu diambil dan dilaksanakan oleh para pihak pada saat membahas mengenai masalah kekerasan terhadap perempuan, dan yang secara lebih khusus manakala membahas mengenai perkembangan kejahatan siber. Berbagai manifestasi kejahatan siber dapat menimbulkan kekerasan terhadap perempuan, sementara pemahaman dan kesadaran perempuan sen- diri akan efek negatif yang mungkin memunculkan kekerasan terhadap dirinya belum disadari betul. Untuk itu perlu diberikannya pendidikan tentang pencegahan kekerasan terhadap perempuan dalam konteks kejahatan siber tersebut.

\section{Ucapan Terima Kasih}

Artikel ini telah dipresentasikan pada pertemuan ilmiah Asosiasi Pengajar dan Peminat Hukum berperspektif Gender se Indonesia (APPHGI) pada 1-3 Oktober 2013 yang lalu di Jakarta. Artikel ini ditulis sebagai salah satu respon atas pentingnya pemahaman bahwasanya kekerasan terhadap perempuan telah mengalami perluasan paradigma dengan munculnya kekerasan secara online, yang terjadi melalui adanya perkembangan media online.

\section{Daftar Pustaka}

\section{Buku-Buku}

Dudeja, V.D. 2002. Cyber Crimes and Law: Crmes in Cyber Space - scams and Frauds, Volume 1, Commonwealth, New Delhi

Golosse, P. 2008. Seputar Kejahatan Hacking: Teori dan Studi Kasus, YPKIK, Jakarta

Pusat Kajian Wanita dan Gender UI. 2004. Hak Azasi Permpuan: Instrumen Hukum untuk Mewujudkan Keadilan Gender. Yayasan Obor, Jakarta

Smith, R.G., Grabosky, P. \& Urbas, G. 2004. Cyber Criminals On Trial, Cambridge University Press, Australia

Sjahdeini, S.R. 2009. Kejahatan dan Tindak Pidana Komputer. Grafiti, Jakarta

UNIFEM. 2004. CEDAW: Mengembalikan Hak-Hak Perempuan, SMK Grafika Desa Putera

\section{Artikel}

Amarsanaa Darinsuren. 2011. "Violence Against Women as A form of Gender Based Violence", Paper, Bangkok, 27 June 2011

KINDAnet, "Women and cybercrime in Kenya: the dark side of ICTS", working document v1

\section{Media Elektronik}

http://women issues.about.com. 2009. "Cyberstalking and Women - Facts and Statistic", Article, diunduh terakhir kali pada 26 September 2013 
detiknews. "Polda Terima 300 Laporan Kejahatan Cyber, Mayoritas Penghinaan di Facebook", Artikel, diunduh terakhir kali pada 26 September 2013

poskota.co.id. "Dihina di FB, seorang wanita melapor ke Polisi", Artikel, diunduh terakhir pada 26 September 2013 tempo.co.id. "Dihina di Facebook, Pegawai Negeri Sipil Lapor Polisi", Artikel, diunduh terakhir kali pada 26 September 2013

http://www.theborneopost.com/2011/01/16/empowering-women-against-cyber-violence/, diunduh terakhir pada 26 September 2013 